\section{$\underset{\substack{\text { hommes } \\ \text { \& migrations }}}{ }$}

\section{Hommes \& migrations}

Revue française de référence sur les dynamiques

migratoires

$1330 \mid 2020$

1973, l'année intense

\title{
Stéphane Beaud, La France des Belhoumi. Portraits de famille (1977-2017)
}

La Découverte, Paris, 2018, 352 pages, $21 €$.

\section{Mustapha Harzoune}

\section{(2) OpenEdition}

Journals

Édition électronique

URL : https://journals.openedition.org/hommesmigrations/11686

DOI : 10.4000/hommesmigrations. 11686

ISSN : 2262-3353

Éditeur

Musée national de l'histoire de l'immigration

Édition imprimée

Date de publication : 17 juillet 2020

Pagination : 240-241

ISBN : 978-2-919040-51-3

ISSN : 1142-852X

Référence électronique

Mustapha Harzoune, "Stéphane Beaud, La France des Belhoumi. Portraits de famille (1977-2017) 》, Hommes \& migrations [En ligne], 1330 | 2020, mis en ligne le 01 juillet 2020, consulté le 04 janvier 2023. URL : http://journals.openedition.org/hommesmigrations/11686 ; DOI : https://doi.org/10.4000/ hommesmigrations. 11686 


\section{La France des Belhoumi. Portraits de famille (1977-2017)}

\author{
Stéphane Beaud, Paris,
}

La Découverte, 2018, 352 p., $21 €$.

Voici un essai de sociologie qui mériterait une audience plus large que celle habituellement dévolue au genre. Puisqu'il faut reléguer le registre de l'émotion à plus tard, commençons ici: l'étude, menée de 2012 à 2017, au sein d'une famille - française! - originaire de l'ouest algérien, riche d'une fratrie de cinq sœurs et trois frères, dévoile, ce que l'auteur appelle lui-même, une «contre histoire»- ou les nouvelles pages d'un roman national.

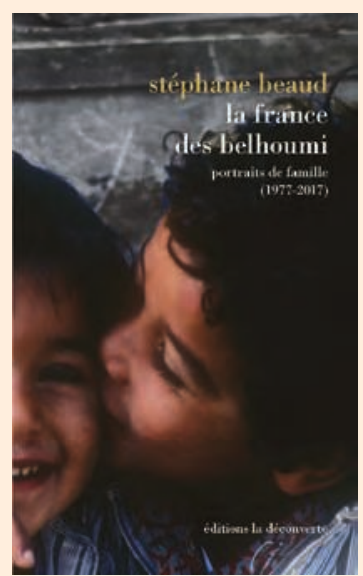

Enquête de terrain, menée sous la forme d'entretiens avec l'ensemble de la famille, il s'est agi pour les uns et les autres de "se» raconter, mais surtout, à travers les trajectoires familiales et individuelles, de dire l'environnement immédiat (la famille, les parents, la fratrie, la cité...), la société (l'école, les formations, le monde professionnel, l'engagement politique, les souhaits et désillusions) et de réagir, après les attentats de 2015, à ce qui s'est imposé à tous: la question de l'islam et du terrorisme.

L'idée de départ vient de Samira, la sœur aînée, née en 1970 en Algérie et cadre à l'Institut de formation des infirmières. Leïla, née en 1973 en Algérie, chargée d'insertion en Mission locale, la deuxième des sœurs aînées, l'a reprise à son compte. Par respect des deux grandes sœurs, par admiration aussi, les autres ont suivi, surtout les trois frangins (Rachid, Mounir, Azzedine). Des trois dernières, seule Nadia, née en France, en 1986, conseillère Pôle emploi a davantage joué «le jeu». Le père, plus à l'aise dans la langue de Kateb Yacine que de Molière, amateur d'aphorismes en arabe dialectal a peu participé aux entretiens, mais il est omniprésent chez ses enfants. Idem pour la mère qui pourtant maîtrise davantage le français.

Si il y a une contre histoire des familles d'origine algériennes en France, elle est ici: la place et le rôle 
du père, la verticalité, l'autonomie et la force des deux aînées nullement entravées et même soutenues; le parcours des trois frangins, parfois «borderline» mais qui ont réussi - grâce aussi au nouveau capital familial constitué par les aînées - à échapper à des mécaniques socio-institutionnelles broyeuses d'hommes; le respect, l'admiration, la loyauté des frères pour leur sœurs; la place de la mère, effacée et gardienne des traditions, sauf quant il s'est agi de défendre la scolarité de ses enfants. Cette contre histoire raconte la dimension générationnelle si importante dans la longue présence algérienne en France: où l'on mesure les différences entre les aînées et les cadettes (10 à 16 ans d'écart), les transformations et bouleversements des contextes socioculturels et politiques entre les années 1980 et les années 2000. Quant à la question religieuse, pas de fantasmes! Il y a de tout chez les Belhoumi: des abstèmes et des siroteurs, des pratiquants à la carte (ramadan, hallal, zakat ou même soufisme) et des laïcs et/ou indifférents. La religion peut être un marqueur identitaire pour autant pas de compromis ici avec les communautaristes et encore moins avec les «barbus» et les «voilées». Enfin, on y est Charlie... ou pas. Les Belhoumi c'est la France sans les «istes», dans sa diversité sociopsycho-culturelle. De cette France qui se bat mais qui doit affronter quelques obstacles de plus. Car cette contre histoire permet de mesurer les ratés, à tout le moins les lenteurs, des cinquante dernières années: comment des énergies, des compétences, le militantisme et le souci de l'autre, si caractéristiques ici (voir notamment les professions), ont été freinés, sous employés, gâchés.

Et puis il y a le registre de l'émotion. On ne sait par quelle alchimie de la rencontre ce livre rend les uns et les autres, familiers et proches. Cette dense étude parvient à faire ce que seuls les romans font: faire de l'émotion une porte d'entrée à l'intelligence. Et même si ce n'est pas l'objet de la démarche, on se surprend à les aimer ces Belhoumi. Tous. À commencer par la déroutante figure du père, et les deux aînées, qui telle la Liberté guidant le peuple, ont tiré vers le haut la geste familiale. Représentatif les Belhoumi? Bien sûr! En tout cas pas moins que certaines réductions. D'ailleurs, il suffit de prendre le métro ou le bus, d'ouvrir un journal, d'allumer sa télé, de lire un livre, d'aller se faire soigner, de consulter un avocat, de se faire une toile, de se rendre dans une administration, de se taper des commerciaux ou des banquiers, d'aller à l'école, au commissariat, au centre de loisirs, dans un bureau de vote... pour savoir que oui, ces Belhoumi sont bougrement représentatifs.

M. H. 